\title{
The Association Between Prepregnancy Body Mass Index and Breastfeeding Duration in Iranian Women
}

\author{
Afsaneh Tehranian,,$^{1,}$ Ladan Hosseini, ${ }^{2}$ Shahin Nariman, ${ }^{3}$ Bita Eslami, ${ }^{4}$ Hadith Rastad, ${ }^{5}$ and Faezeh \\ Aghajani ${ }^{6}$ \\ ${ }^{1}$ Department of Obstetrics and Gynecology, Arash Women's Hospital, Tehran University of Medical Sciences, Tehran, Iran \\ ${ }^{2}$ Research Development Center, Arash Women's Hospital, Tehran University of Medical Sciences, Tehran, Iran \\ ${ }^{3}$ Department of Pediatrics and Neonatology, Arash Women's Hospital, Tehran University of Medical Sciences, Tehran, Iran \\ ${ }^{4}$ Breast Disease Research Center (BDRC), Tehran University of Medical Sciences, Tehran, Iran \\ ${ }^{5}$ Public Health School, Tehran University of Medical Sciences, Tehran, Iran \\ ${ }^{6}$ Medical School, Tehran University of Medical Sciences, Tehran, Iran \\ "Corresponding author: Afsaneh Tehranian, Department of Obstetrics and Gynecology, Arash Women's Hospital, Tehran University of Medical Sciences, Tehran, Iran. Tell: \\ +98-2177719922, E-mail: afsanehtehranian@yahoo.com
}

Received 2017 May 01; Accepted 2017 July 25.

\begin{abstract}
Background: The World Health Organization has recommended exclusive breastfeeding for 6 months. Breastfeeding success may be influenced by different factors.

Objectives: The aim of this study was to determine the association between prepregnancy body mass index (BMI) and breastfeeding duration in Iranian mothers.

Methods: This prospective cohort study was conducted at Arash Women's Hospital in Tehran, Iran. The analysis included 593 women, followed from pregnancy until 6 months postpartum. A logistic regression model was used to determine the association between prepregnancy BMI and exclusive breastfeeding duration and initiation.

Results: Women with prepregnancy BMI above $25 \mathrm{~kg} / \mathrm{m}^{2}$ had a higher risk (almost twice) of not initiating breastfeeding or breastfeeding for less than 1 month after delivery, compared to pregnant women who had a normal weight. In this study, adjustments were made for confounding factors, such as age, education level, mode of delivery, mother's opinion of breastfeeding, and mother's occupation.

Conclusions: This study showed that women who had a normal prepregnancy weight were more likely to continue breastfeeding for 6 months, while obese and overweight women had a shorter duration of breastfeeding in comparison with normal-weight women.
\end{abstract}

Keywords: Prepregnancy Body Mass Index, Breastfeeding Duration, Gestational Weight Gain

\section{Background}

The prevalence of obesity is growing worldwide, and this condition has become a public health problem (1). Obesity is a risk factor for not only chronic diseases (2), but also maternal and prenatal complications (3). According to previous studies, the rate of hypertension, preeclampsia, gestational diabetes, dystocia $(4,5)$, cesarean section, prolonged delivery, intrauterine fetal death, and congenital abnormalities $(3,6)$ is higher in obese mothers in comparison with others.

Numerous factors can influence the initiation of breastfeeding, such as mother's weight, ethnicity, occupation, and economic status. Additionally, a large number of studies have shown an adverse association between maternal obesity and breastfeeding initiation and duration (7-10). Rasmussen indicated that risk of early breastfeeding cessation is approximately $14.4 \%$ among obese class III mothers versus 3.5\% in normal-weight women with body mass index (BMI) above $26 \mathrm{~kg} / \mathrm{m}^{2}$ (11).

The etiology of the association between maternal obesity and breastfeeding initiation and duration is unknown, although some social factors seem to influence this relationship (12). In Iran, Islam has suggested mothers to breastfeed their children for 2 years.

\section{Objectives}

With this background in mind, in this study, we aimed to determine the association of prepregnancy BMI with breastfeeding initiation and duration in Iranian mothers.

\section{Methods}

This prospective study was performed among singleton pregnant women in the first trimester of pregnancy, 
admitted to the perinatal clinic of Arash Women's Hospital. A total of 718 women were consecutively recruited in this study during 2007-2011. Women without hyperemesis gravidarum, medical complications during pregnancy (affecting breastfeeding), infant admission to the neonatal intensive care unit in the first few days of life, child death, or abortion were recruited.

In the first prenatal visit, in order to calculate prepregnancy BMI, self-report prepregnancy weight and height were recorded. For gathering further data, a checklist consisting of information, such as mother's opinion of breastfeeding, occupation, education level, and parity, was completed in face-to-face interviews with each mother. According to the WHO definition, exclusive breastfeeding was defined as only giving breast milk to the baby, without other liquids or solids, except those containing vitamins or medicines (10).

Women were classified into 2 BMI categories: normal weight $\left(<25 \mathrm{~kg} / \mathrm{m}^{2}\right)$ and overweight $\left(\geq 25 \mathrm{~kg} / \mathrm{m}^{2}\right)$. Gestational weight gain was categorized according to the Institute of Medicine (IOM) recommendations (13). Finally, breastfeeding data were collected 6 months after birth, using a self-administered checklist via phone interviews. The present study was approved by the Institutional Review Board of Tehran University of Medical Sciences, and informed consents were obtained from the participants.

Statistical analyses were performed using SPSS version 16.0 (SPSS Inc., Chicago, IL, USA). Quantitative data are presented as mean \pm standard deviation, and qualitative data are presented as number with percentages. Chi square and t test were used when appropriate. Considering the significant association between prepregnancy BMI and gestational weight gain, two logistic regression models (backward elimination) were used to determine the association of prepregnancy BMI and gestational weight gain with exclusive breastfeeding duration.

Breastfeeding for at least 1 to 6 months postpartum was the primary outcome of this study. In both logistic regression models, other variables, including age, education, mode of delivery, parity, mother's occupation, and mother's opinion of breastfeeding, were separately entered in the binary logistic model (univariate model), and the crude odds ratios (ORs) were obtained. Variables with P-value below 0.02 were entered in the model. P-value less than 0.05 was considered statistically significant.

\section{Results}

Overall, 718 pregnant women participated in this study, 115 of whom missed the follow-ups and 10 pregnancies ended in abortion. Finally, the information of 593 women was collected. The average age, weight gain during pregnancy, and other demographic characteristics of the participants are presented in Table 1 . In this study, 33.3\%, 18.7\%, and $48 \%$ of the participants gained adequate, inadequate, and excessive weight during pregnancy, respectively, according to the IOM recommendations.

The subjects were categorized into 2 groups: normal weight (BMI $<25 \mathrm{~kg} / \mathrm{m}^{2}$ ) and overweight or obese ( $>25$ $\left.\mathrm{kg} / \mathrm{m}^{2}\right)$. A large proportion of women with prepregnancy overweight and obesity were older and had a higher parity, compared to normal-weight mothers; they were mostly employed and had lower education levels. In addition, preterm delivery and high birth weight of infants were significantly more common in overweight and obese mothers (Table 1).

Among 593 participants, 42 (7.1\%) never initiated breastfeeding or failed to exclusively breastfeed their infants for at least 1 month. Among those who breastfed their infants for at least 1 month (n, 551), 36 (6.5\%) breastfed for less than 3 months, 29 (5.3\%) stopped breastfeeding within 3-6 months, and 486 (88.2\%) continued breastfeeding for 6 months. The frequency of exclusive breastfeeding duration was higher in the normal-weight group versus the overweight group (94.3\% vs. $90.4 \%$ ); this trend was seen at all times of breastfeeding ( $<3$ months, $3-6$ months, and 6 months), although the difference between the groups was insignificant (Table 1).

Women who did not breastfeed their infants were older than others ( 27.8 vs. 26.6 years) and had higher education (32.3\% vs. $17.9 \%)$ and a higher cesarean section rate (77\% vs. 58\%) (Table 2). Breastfeeding for at least 1 to 6 months was the outcome of both logistic regression models. The crude and adjusted ORs for different characteristics are presented in Table 3 (for variables with $\mathrm{P}<0.20$ ).

In the unadjusted analysis, normal-weight mothers were more likely to exclusively breastfeed their infants for 6 months; however, the difference between the groups was not significant (OR, 1.55; 95\% CI, 0.86 to 2.88 ; $\mathrm{P}=0.14$ ). These results changed considerably after adjustments for the confounding factors, and the significance of association between prepregnancy BMI and breastfeeding duration was demonstrated (OR, 2; 95\% CI, 1.06 to 3.7).

Moreover, after adjustments for the confounding factors, women with academic education were 5 times more likely to unsuccessfully initiate breastfeeding, compared to women with education under high school diploma (OR, 5.2; 95\% CI, 1.95 to 14.1). Additionally, cesarean section (OR, 2; $95 \%$ CI, 1.02 to 4.11) decreased the likelihood of breastfeeding duration (Table 3). After adjustments for the confounding factors, gestational weight gain did not show any significant effects on successful initiation of breastfeeding (OR, $1.4 ; 95 \% \mathrm{CI}, 0.57$ to 3.4 ). 
Table 1. The Demographic and Obstetric Characteristics Based on Prepregnancy BMI

\begin{tabular}{|c|c|c|c|c|}
\hline & Total & BMI $<25 \mathrm{~kg} / \mathrm{m}^{2}$ & BMI $\geq 25 \mathrm{~kg} / \mathrm{m}^{2}$ & P-Value \\
\hline \multicolumn{5}{|l|}{ Continuous variables* } \\
\hline Age & $26.68(4.62)$ & $26.12(4.53)$ & $27.46(4.64)$ & $<0.001$ \\
\hline Parity & $1.5(0.69)$ & $1.41(0.62)$ & $1.63(0.77)$ & $<0.001$ \\
\hline Weight gain & $14.08(5.3)$ & $14.07(4.74)$ & $14.12(6)$ & 0.97 \\
\hline Birth weight & $3206.35(416.07)$ & $3178.04(389.6)$ & $3248.86(454.68)$ & 0.05 \\
\hline \multicolumn{5}{|l|}{ Categorical variables ${ }^{* *}$} \\
\hline \multicolumn{5}{|l|}{ Education } \\
\hline Under diploma & $221(35.8)$ & $106(30.3)$ & $103(43.8)$ & \\
\hline Diploma & $264(44.7)$ & $170(48.6)$ & $91(38.7)$ & 0.004 \\
\hline Bachelor's degree & $115(19.5)$ & $74(21.1)$ & $41(17.4)$ & \\
\hline \multicolumn{5}{|l|}{ Occupation } \\
\hline Housewife & $547(92.6)$ & $333(94.9)$ & $210(89.4)$ & \\
\hline Employed & $44(7.4)$ & $189(5.1)$ & $25(10.6)$ & 0.012 \\
\hline \multicolumn{5}{|l|}{ Mother's opinion of breastfeeding } \\
\hline Important & $523(96.9)$ & $320(97)$ & $198(96.6)$ & 0.85 \\
\hline Lack of interest & $17(3.1)$ & $10(3)$ & $7(3.4)$ & \\
\hline \multicolumn{5}{|l|}{ Delivery } \\
\hline Natural vaginal delivery & $238(40.3)$ & $147(41.8)$ & $88(37.6)$ & 0.31 \\
\hline Cesarean section & $353(59.7)$ & $205(58.2)$ & $146(62.4)$ & \\
\hline \multicolumn{5}{|l|}{ Icter } \\
\hline Yes & $175(29.6)$ & $109(31.1)$ & $66(28.1)$ & 0.44 \\
\hline No & $416(70.4)$ & $242(68.9)$ & $169(71.9)$ & \\
\hline \multicolumn{5}{|l|}{ Breastfeeding } \\
\hline Never breastfed & $42(7.1)$ & $20(5.7)$ & $22(9.4)$ & \\
\hline Breastfeeding $<3 \mathrm{~m}$ & $36(6.1)$ & $22(6.2)$ & $41(6)$ & 0.13 \\
\hline Breastfeeding 3-6 m & $29(4.9)$ & $19(5.4)$ & $9(3.8)$ & \\
\hline Breastfeeding for 6 months & $486(82)$ & $292(82.7)$ & $190(80.9)$ & \\
\hline \multicolumn{5}{|l|}{ Anomaly } \\
\hline Yes & $5(0.8)$ & $2(0.6)$ & $3(1.3)$ & 0.35 \\
\hline No & $588(99.2)$ & $351(99.4)$ & $232(98.7)$ & \\
\hline \multicolumn{5}{|l|}{ Sex } \\
\hline 2 & $305(51.4)$ & $169(47.9)$ & $134(57)$ & 0.03 \\
\hline 1 & $288(48.6)$ & $184(52.1)$ & $101(43)$ & \\
\hline \multicolumn{5}{|l|}{ Gestational age } \\
\hline Term & $514(78.4)$ & $313(89.4)$ & $196(84.1)$ & 0.009 \\
\hline Preterm & $55(9.4)$ & $23(6.6)$ & $32(13.7)$ & \\
\hline Postterm & $19(3.2)$ & $14(4)$ & $5(2.1)$ & \\
\hline
\end{tabular}

Abbreviation: BMI, body mass index.

\section{Discussion}

The purpose of this study was to determine the association between prepregnancy BMI and breastfeeding duration in Iranian mothers. In an unadjusted analysis, the duration of breastfeeding between obese and normal-weight women was not significantly different. However, after adjusting for the confounding factors, the significance of the association changed, and women with prepregnancy obesity or overweight (BMI > $25 \mathrm{~kg} / \mathrm{m} 2$ ) had a higher risk (almost twice) of not initiating breastfeeding or breastfeeding for less than 1 month in comparison with women with normal prepregnancy weight. The present study suggested prepregnancy obesity or overweight as one of the reasons for the cessation of breastfeeding.

The results of the current research are in consistence with the findings of previous studies. Oddy W et al. demonstrated a reduction in breastfeeding duration in obese and overweight mothers (10). In addition, in a study by Susan $\mathrm{M}$ et al., a shorter duration of breastfeeding was reported 
Table 2. The Demographic and Obstetric Characteristics, Based on Successful Initiation of Breastfeeding

\begin{tabular}{|c|c|c|c|}
\hline & Successful Initiation of Breastfeeding & Unsuccessful Initiation of Breastfeeding & P-Value \\
\hline \multicolumn{4}{|l|}{ Continuous variables* } \\
\hline Age & $26.68(4.55)$ & $27.87(5.02)$ & 0.02 \\
\hline Parity & $1.5(0.68)$ & $1.4(0.69)$ & 0.3 \\
\hline Weight gain & $14.23(5.18)$ & $13.61(5.18)$ & 0.34 \\
\hline \multicolumn{4}{|l|}{ Categorical variables** } \\
\hline \multicolumn{4}{|l|}{ Education } \\
\hline Under diploma & $203(38.6)$ & $8(12.9)$ & \\
\hline Diploma & $229(43.5)$ & $34(54.8)$ & $0<0001$ \\
\hline Bachelor's degree & $94(17.9)$ & $20(32.3)$ & \\
\hline \multicolumn{4}{|l|}{ Occupation } \\
\hline Housewife & $491(93.5)$ & $54(87.1)$ & \\
\hline Employed & $34(6.5)$ & $8(12.9)$ & 0.06 \\
\hline \multicolumn{4}{|c|}{ Mother's opinion of breastfeeding } \\
\hline Lack of interest & $10(2.1)$ & $7(11.9)$ & \\
\hline Important & $469(97.9)$ & $52(88.1)$ & $<0.0001$ \\
\hline \multicolumn{4}{|l|}{ Mode of delivery } \\
\hline Normal vaginal delivery & $222(42)$ & $14(23)$ & 0.004 \\
\hline Cesarean section & $306(58)$ & $47(77)$ & \\
\hline \multicolumn{4}{|l|}{ BMI $\left(\mathrm{kg} / \mathrm{m}^{2}\right)$} \\
\hline$<25$ & $325(61.4)$ & $31(50)$ & 0.08 \\
\hline$>25$ & $204(38.6)$ & $31(50)$ & \\
\hline \multicolumn{4}{|l|}{ Gestational age } \\
\hline Term & $510(88.2)$ & $51(81.4)$ & \\
\hline Preterm & $46(11.8)$ & $8(18.6)$ & 0.31 \\
\hline \multicolumn{4}{|c|}{$\begin{array}{l}\text { Gestational weight gain (GWG) according to the IOM } \\
\text { recommendation }\end{array}$} \\
\hline GWG $<$ IOM & $90(18.3)$ & $11(18)$ & 0.9 \\
\hline $\mathrm{GWG}=\mathrm{IOM}$ & $165(33.6)$ & $21(34.4)$ & \\
\hline GWG > IOM & $236(48.1)$ & $29(47.5)$ & \\
\hline
\end{tabular}

among obese and overweight Australian mothers (14). Hilson and Li also showed that women with BMI $>30 \mathrm{~kg} / \mathrm{m}^{2}$ had a shorter duration of breastfeeding, while in our study, overweight, as well as obese women, were at a higher risk of breastfeeding cessation (15).

In the current study, $18.7 \%$ and $48 \%$ of the participants gained inadequate and excessive weight during pregnancy, respectively, according to the IOM recommendations. In a study by Manios, 37.1\% and 31.1\% of Greece women (n, 2374) had inadequate and excessive gestational weight gain, respectively (16). Moreover, in a study conducted in Guilan, North of Iran, the percentage of urban women who gained weight above the IOM recommendation was $10 \%$, while $41.1 \%$ gained weight less than the recommended range (17).

In the present study, the mean gestational weight gain according to the IOM recommendation was not in association with successful initiation of breastfeeding after adjustments for the confounding factors. Because of in- sufficient sample size, we could not evaluate the association of gestational weight gain (according to the maternal prepregnancy BMI) with initiation and duration of breastfeeding. Additionally, Manios et al. studied 2375 preschool children, aged 1-5 years, in Greece. In their study, high maternal prepregnancy BMI had a negative association with the initiation of breastfeeding, but not maternal gestational weight gain (16).

Furthermore, Winkvist et al. evaluated 49669 women in a large population-based study (the Norwegian Mother and Child Cohort Study or MOBa) between 1999 and 2008. A significant association was found between high prepregnancy BMI and unsuccessful initiation of breastfeeding, as well as all categories of gestational weight gain in women with prepregnancy obesity, overweight, or underweight (13). Hilson et al. also conducted a study on 2783 American women, who delivered between 1997 and 1998 and initiated breastfeeding. The results demonstrated that obese, overweight, and underweight women with gesta- 
Table 3. The Logistic Regression Model for the Association of Maternal Prepregnancy BMI with Breastfeeding Duration for at Least 1 Month after Delivery

\begin{tabular}{|c|c|c|c|}
\hline \multirow{2}{*}{ Variables } & & \multicolumn{2}{|c|}{ Unsuccessful Initiation of Breastfeeding } \\
\hline & & Crude OR & Adjusted $\mathrm{OR}^{\mathrm{a}}$ \\
\hline \multirow{3}{*}{ Age } & OR & 1.05 & 1.03 \\
\hline & $95 \% \mathrm{CI}$ & 0.99 to 1.12 & 0.96 to 1.11 \\
\hline & P.V & 0.08 & 0.3 \\
\hline \multicolumn{4}{|l|}{ BMI $\left(\mathrm{kg} / \mathrm{m}^{2}\right)$} \\
\hline \multirow{3}{*}{ BMI $>25$} & OR & 1.55 & 2 \\
\hline & $95 \% \mathrm{CI}$ & 0.8 to 2.88 & 1.1 to 3.8 \\
\hline & P.V & 0.1 & 0.02 \\
\hline BMI $<25$ & $\mathrm{OR}$ & 1 & 1 \\
\hline \multicolumn{4}{|l|}{ Occupation } \\
\hline \multirow{3}{*}{ Housewife } & OR & 0.42 & 1.1 \\
\hline & $95 \% \mathrm{CI}$ & 0.18 to 1.02 & 0.3 to 3.3 \\
\hline & P.V & 0.05 & 0.8 \\
\hline Employed & OR & 1 & 1 \\
\hline \multicolumn{4}{|c|}{ Mother's opinion of breastfeeding } \\
\hline \multirow{3}{*}{ Lack of interest } & OR & 6.41 & 5.23 \\
\hline & $95 \% \mathrm{CI}$ & 2.25 to 18.22 & 1.7 to 15.9 \\
\hline & P.V & $<0.001$ & 0.004 \\
\hline Important & $\mathrm{OR}$ & 1 & 1 \\
\hline \multicolumn{4}{|l|}{ Mode of delivery } \\
\hline \multirow{3}{*}{ Cesarean section } & $\mathrm{OR}$ & 2.3 & 2 \\
\hline & $95 \% \mathrm{CI}$ & 1.16 to 4.7 & 1.02 to 4.11 \\
\hline & P.V & 0.01 & 0.04 \\
\hline Vaginal delivery & OR & 1 & 1 \\
\hline \multicolumn{4}{|l|}{ Education } \\
\hline \multirow{3}{*}{ Diploma } & OR & 3.57 & 4 \\
\hline & $95 \% \mathrm{CI}$ & 1.4 to 8.8 & 1.5 to 11 \\
\hline & P.V & 0.006 & 0.005 \\
\hline \multirow{3}{*}{ University education } & OR & 5.92 & 5.87 \\
\hline & $95 \% \mathrm{CI}$ & 2.2 to 15.5 & 2 to 16.9 \\
\hline & P.V & $<0.001$ & 0.001 \\
\hline Under diploma & OR & 1 & 1 \\
\hline
\end{tabular}

${ }^{\mathrm{a}}$ Variables entered in step 1: age, education level, mode of delivery, mother's opinion of breastfeeding, mother's occupation, and BMI. Variables entered in step 2: age education level, mode of delivery, mother's opinion of breastfeeding, and BMI. Variables entered in step 3: education level, mode of delivery, mother's opinion of breastfeeding, and BMI. Variables entered in step 4: education level, mother's opinion of breastfeeding, and BMI.

tional weight gain above the IOM recommendations were at risk of early discontinuation of exclusive breastfeeding (15).

In the present study, after adjusting for the confounding factors, a higher risk of breastfeeding cessation was observed in mothers with a higher education level, compared to women with education below high school diploma. Rakhshani et al. in a historical cohort of 1264 Iranian children (under 3 years) in Southeast of Iran found that maternal education had a negative influence on breastfeeding duration (18). Moreover, in a study by Marandi (19), high education level did not influence successful breastfeeding, and Iranian women needed to be educated about breastfeeding.

Overall, maternal obesity may affect the breastfeeding ability in ways unrelated to the initiation and knowledge of breastfeeding. A large number of studies have reported that overweight and obese women have an increased risk of pregnancy and delivery complications, such as preterm birth and cesarean section, which may be among the reasons for delayed lactogenesis or low milk supply in obese mothers (2, 20-22). In the present study, the prevalence of preterm birth was significantly higher in overweight and obese women, compared to others; moreover, risk of cesarean section was higher, but the difference was insignificant. Women with cesarean section had a higher risk (almost twice) of not initiating breastfeeding or breastfeeding for less than 1 month after delivery.

Different patterns of effective hormones in initiating and maintaining breastfeeding in obese women have been 
proposed as a theory. Considering the higher progesterone level in obese women in comparison with normal-weight women, they experience delayed lactogenesis $(2,13,23)$. In addition, infants of overweight mothers are unable to easily grasp the large breasts of their mothers. Therefore, they grow dissatisfied with their mother's milk, which in turn reduces the duration of breastfeeding for these mothers $(21,24)$.

We eliminated the possible effects of confounding factors, such as age, education level, mode of delivery, mother's opinion of breastfeeding, and mother's occupation, on the duration of breastfeeding, which is a strength of the present study. We also designed a prospective cohort study, which is another point of strength in this research. On the other hand, according to the findings, socioeconomic status may affect breastfeeding initiation and duration; however, in this study, we missed this factor and failed to evaluate its effect on breastfeeding duration.

\subsection{Conclusion}

Numerous factors can affect the initiation of breastfeeding, such as maternal race, ethnicity, and education (8). It seems that BMI is one of the factors, which can affect breastfeeding duration and initiation. Breast milk contains the essential nutrients, which play an important role in the infant's health (25). Many studies have shown the advantages of exclusive breastfeeding for 6 months in infants, such as protection against early diseases. In this regard, Ip S. et al. reported similar results in their review article. It should be noted that exclusive breastfeeding is the newborn's first chance to have a healthy and productive life $(26,27)$. The low rate of breastfeeding has adverse effects on the mother and infant's health, as well as mother's socioeconomic status (26).

WHO has recommended exclusive breastfeeding for 6 months (1). Overall, breastfeeding success may be affected by different variables (12). In this article, we showed that obese or overweight mothers have a shorter duration of exclusive breastfeeding in comparison with women of normal weight. Therefore, it seems effective to encourage overweight and obese women to lose weight before pregnancy. Moreover, families and healthcare systems should support these women for successful breastfeeding during 6 months after delivery. Maternal gestational weight gain may not influence breastfeeding duration and initiation.

\section{References}

1. World Health Organization . Obesity: Preventing and managing the global epidemic. Geneva: World Health Organization; 1998.

2. Field AE, Coakley EH, Must A, Spadano JL, Laird N, Dietz WH, et al. Impact of overweight on the risk of developing common chronic diseases during a 10-year period. Arch Intern Med. 2001;161(13):1581-6. [PubMed: 11434789].
3. Linne Y. Effects of obesity on women's reproduction and complications during pregnancy. Obes Rev. 2004;5(3):137-43. doi: 10.1111/j.1467789X.2004.00147.x. [PubMed: 15245382].

4. Huda SS, Brodie LE, Sattar N. Obesity in pregnancy: prevalence and metabolic consequences. Semin Fetal Neonatal Med. 2010;15(2):70-6. doi:10.1016/j.siny.2009.09.006. [PubMed:19896913].

5. Watkins ML, Rasmussen SA, Honein MA, Botto LD, Moore CA. Maternal obesity and risk for birth defects. Pediatrics. 2003;111(5 Pt 2):1152-8. [PubMed: 12728129].

6. Spellacy WN, Miller S, Winegar A, Peterson PQ. Macrosomiamaternal characteristics and infant complications. Obstet Gynecol. 1985;66(2):158-61. [PubMed: 4022478].

7. Mehta UJ, Siega-Riz AM, Herring AH, Adair LS, Bentley ME. Maternal obesity, psychological factors, and breastfeeding initiation. Breastfeed Med. 2011;6(6):369-76. doi: 10.1089/bfm.2010.0052. [PubMed: 21492019].

8. Hauff LE, Leonard SA, Rasmussen KM. Associations of maternal obesity and psychosocial factors with breastfeeding intention, initiation, and duration. Am J Clin Nutr. 2014;99(3):524-34. doi: 10.3945/ajcn.113.071191. [PubMed: 24401717]

9. Hernandez L. Association of prepregnancy bmi and pregnancy weight gain with breastfeeding practices, Florida 2008-2011. CityMatCH Leadership and Epidemiology Conference. Florida. .

10. Oddy WH, Li J, Landsborough L, Kendall GE, Henderson S, Downie J. The association of maternal overweight and obesity with breastfeeding duration. J Pediatr. 2006;149(2):185-91. doi: 10.1016/j.jpeds.2006.04.005. [PubMed: 16887431].

11. Rasmussen KM. Association of maternal obesity before conception with poor lactation performance. Annu Rev Nutr. 2007;27:103-21. doi: 10.1146/annurev.nutr.27.061406.093738. [PubMed: 17341160].

12. Veghari G. Association of economic status with breastfeeding rates in Northern Iran. J Pak Med Assoc. 2012;62(8):756-9. [PubMed: 23862243]

13. Winkvist A, Brantsaeter AL, Brandhagen M, Haugen M, Meltzer HM, Lissner L. Maternal Prepregnant Body Mass Index and Gestational Weight Gain Are Associated with Initiation and Duration of Breastfeeding among Norwegian Mothers. J Nutr. 2015;145(6):1263-70. doi: 10.3945/jn.114.202507. [PubMed: 25904732].

14. Donath SM, Amir LH. Maternal obesity and initiation and duration of breastfeeding: data from the longitudinal study of Australian children. Matern Child Nutr. 2008;4(3):163-70. doi:10.1111/j.17408709.2008.00134.x. [PubMed: 18582350].

15. Hilson JA, Rasmussen KM, Kjolhede CL. Excessive weight gain during pregnancy is associated with earlier termination of breast-feeding among White women. J Nutr. 2006;136(1):140-6. [PubMed: 16365073].

16. Manios Y, Grammatikaki E, Kondaki K, Ioannou E, Anastasiadou A Birbilis $M$. The effect of maternal obesity on initiation and duration of breast-feeding in Greece: the GENESIS study. Public Health Nutr. 2009;12(4):517-24. doi: 10.1017/S1368980008002838. [PubMed: 18547456].

17. Maddah M, Nikooyeh B. Urban and rural differences in pregnancy weight gain in Guilan, northern Iran. Matern Child Health J. 2008;12(6):783-6. doi: 10.1007/s10995-007-0273-5. [PubMed: 17694425].

18. Rakhshani F, Mohammadi M. Continuation of breastfeeding: is this a problem in Southeast Iran? Breastfeed Med. 2009;4(2):97-100. doi: 10.1089/bfm.2008.0038. [PubMed: 19210133].

19. Marandi A, Afzali HM, Hossaini AF. The reasons for early weaning among mothers in Teheran. Bull World Health Organ. 1993;71(5):561-9. [PubMed: 8261559].

20. Seligman LC, Duncan BB, Branchtein L, Gaio DS, Mengue SS, Schmidt MI. Obesity and gestational weight gain: cesarean delivery and labor complications. Rev Saude Publica. 2006;40(3):457-65. [PubMed: 16810370]. 
21. Baker JL, Michaelsen KF, Sorensen TI, Rasmussen KM. High prepreg nant body mass index is associated with early termination of full and any breastfeeding in Danish women. Am JClin Nutr. 2007;86(2):404-11. [PubMed: 17684212].

22. Haroon S, Das JK, Salam RA, Imdad A, Bhutta ZA. Breastfeeding promotion interventions and breastfeeding practices: a systematic review. BMC Public Health. 2013;13 Suppl 3:S20. doi: 10.1186/1471-2458-13-S3-S20. [PubMed: 24564836].

23. Chapman DJ, Perez-Escamilla R. Identification of risk factors for delayed onset of lactation. J Am Diet Assoc. 1999;99(4):450-4. doi: 10.1016/S0002-8223(99)00109-1. [PubMed:10207398] quiz 455-6.

24. Wojcicki JM. Maternal prepregnancy body mass index and initiation and duration of breastfeeding: a review of the literature. $J$ Womens Health (Larchmt). 2011;20(3):341-7. doi: 10.1089/jwh.2010.2248. [PubMed: 21434834].

25. Gartner LM, Morton J, Lawrence RA, Naylor AJ, O'Hare D, Schanler RJ, et al. Breastfeeding and the use of human milk. Pediatrics. 2005;115(2):496-506. doi: 10.1542/peds.2004-2491. [PubMed: 15687461].

26. Olang B, Farivar K, Heidarzadeh A, Strandvik B, Yngve A. Breastfeeding in Iran: prevalence, duration and current recommendations. Int Breastfeed J. 2009;4:8. doi: 10.1186/1746-4358-4-8. [PubMed:19656361].

27. Slusser W. Breastfeeding and maternal and infant health outcomes in developed countries. AAP Grand Rounds. 2007;18(2):15-6. 